\title{
Can Video Support City-Based Communities?
}

\author{
Raquel Navarro-Prieto and Nidia Berbegal \\ Barcelona Media - Innovation Center, Barcelona, Spain \\ Raquel. Navarro@barcelonamedia.org, \\ Nidia. Berbegal aupf . edu
}

\begin{abstract}
The goal of our research has been to investigate the different ways in with using new communication technologies, especially mobile multimedia communications, could support the city-based communities. In this paper we review the research done about the effect of mobile technology, specially mobile video, into communities' communication patterns, and highlight the new challenges and gaps still not covered in this area. Finally, we will describe how we have tried to respond to these challenges by using User Centered Design in two very different types of communities: women associations, and elderly people.
\end{abstract}

\section{Introduction}

The goal of our research was to understand the role of mobile multimedia applications, with special emphasis on video, in the communities that already exist in cities. While a lot of research have focus on virtual communities, less attention have been paid to physical communities what would benefit from the use of new mobile technologies.

Our research has been conducted as part of the EC funded IST project ICING (Innovative Cities of the Next Generation), which goal is to reach a model of a city more responsive to the citizen through the usage of multi-access and multi-modal infrastructures to explore new ways of communication and interaction.

Indeed, although in the last years, there has been several papers about different applications of mobile video and TV [1] most of the research have been focus on either a passive consumption of videos and TV content; or on peer to peer exchange of videos (without studying the impact into a group). Several applications and services have been build recently trying to help communities based in a particular city or an area (like an university campus), so far they are including chat, voice conversations, emails and SMS [2,3,4] but only now video is starting to emerge as an complementary way to communicate.

In our paper we will review the exiting literature in the areas mentioned above starting with defining the scope of our definition of community. Regarding the usage of video first, we will look at the usage of video on remote groups and virtual communities. Second, we will explore the challenges introduce by the new emerging technologies that facilitate mobile social networks. After that, we will see how the existing literature does not answer the question about how these technologies have an 
effect in the communication needs of physically based communities. In order to understand the effect of mobile multimedia applications on these special types of communities we will describe our work in the ICING project, using User Centered Design approach with several already existing communities of citizens.

\section{Towards a Definition of Community}

The term "community" has not a unique definition, but covers a wide range of social links. One of the broadest definitions of community considers that a community is a collection of livings that form a social group characterized by a territorial or demographical link or that share common interests, hobbies or ideological convictions that establish personal relationships between them through physical and/or virtual environments. According to [5] we have several ways to classify the nature of a community Demographic, Geographical and Topical Communities. In Figure 1, we illustrate the cross of these categories with the way its members communicate to each other, which is the focus of our study:

If defining the term "community" was not simple, trying to define "virtual communities" is, indeed, an even harder difficult task. Several definitions have been written by different authors, focusing on different aspects of these communities. As a consequence sometimes they not seem to be defining the same term.

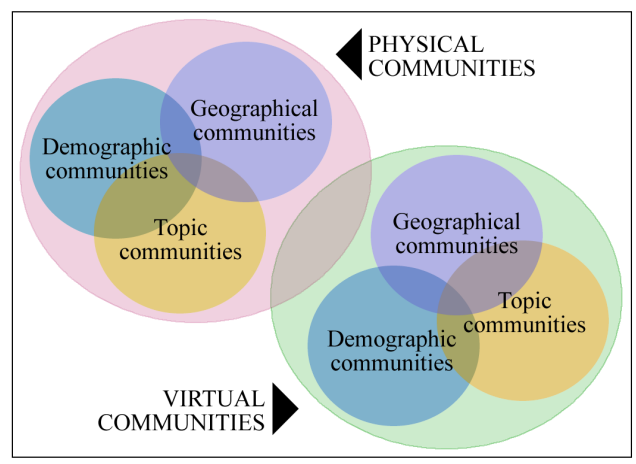

Fig. 1. Communities' classification

Several definitions from well-known e-community specialists have been found in [6]. For instance, according to Amy Jo Kim, a virtual community "is a group of people who gather together around a shared purpose, activity, or interest". Because of the lack of a common physical location as a factor of their identity, this definition implies that its members have to use some kind of virtual tools to communicate to each other and to be able to establish personal relations. There is a debate among sociologists about how cyberspace communities' behaviours relate to physical communities theories. In the essence, virtual and physical communities do not differ so much, both involve personal relationships among the different people that share same interests, so a virtual community is, in a sense, "a community that happens to 
exist online rather than in the physical word" [7]. Online communities have many characteristics borrowed from real-world communities [8], [9]. It is outside the scope of this paper to review all the characteristics of these communities.

\section{Usage of Video on Remote Groups and Virtual Communities}

The usages of video to enhance people collaborating in teams which members are remotely located have been investigated since the early times of HCI. During the 90s a several researchers investigated the advantages and when would it be more effective to use video-mediated communication among groups collaborating remotely. The hypothesis that they were trying to test was whether video could substitute face-toface communication effectively $[10,11,12]$. Therefore, the research questions were focus on comparing users interacting with video versus face-to-face situations. For instance, the work from Credé and Sniezek [13] compared 94 groups of size three while completing a estimation task interacting either by video-conferencing or face-to face collocated in the same room. Their results show that the video-conferencing groups scored lower than the face-to-face in several metrics as level of confidence (being lower and more accurate in the video-conferencing groups). On the other hand "there were no significant differences between the two interaction media on the following outcome dimensions: accuracy; overconfidence; commitment to the group decision; size of credible intervals; improvement over average initial individual estimates; and the number of beliefs discussed or learned".

Other studies found different advantages of one type of communication depending on several variables [14]. It seems that Video-mediated communication, as well as other forms of remote interpersonal communication are distinctive by the nature of the medium from which they are constituted. We agree with Fels and Weiss [15] that "each form of communication has particular strengths and weaknesses". Therefore, the goal should be to define the interactions needed to complete a particular task and to select the most efficient way to provide then. Although most of the research in the area of video mediated communication has been done in with remote groups that it is not equivalent to the definition of community that we show bellow, we think that their findings are interesting for our work.

Focusing now on research about communities (as they have been defined in the previous section) people have been communicating using online spaces since the beginning of the Internet, "including prior to the World Wide Web, when BBS or electronic bulletin boards and email loops connected folks across time and space" [16]. Nowadays, online communities are web-based communities, mostly held by chats, discussion forums, online salons, mailing lists, bulletin boards, MUDs (multiuser dimension), MOOS (Multi-user objected oriented), listservs, etc. or combinations of these software programs along with web pages; in addition video communications between virtual community members are shyly increasing. Nevertheless, most of the research on virtual communities has not contemplated the usage of video. We believe that one explanation for that is that in a lot of the virtual communities users have a fake identity using an avatar that does not correspond to their image.

In contrast with the lack of research on the impact of video exchange on the life of online communities, the exchange of videos is an well know recent phenomenon 
growing every day. According to the Timothy Tuttle the VP of AOL Video [17] the numbers are "10 billion videos streamed every month, 60 billion dollar market opportunity, internet video doubling every 6 months". It is clear that people like to share the videos, most of the time user generated videos, inside small and wide communities. A great example is the popularity of the site YouTube [18], that allow not only sharing but making links to the videos in blog and personal webs.

\section{New Research Challenges of Mobile Multimedia Applicatiosns}

In addition the research challenges of the use of video in online communities, recently the possibility of exchanging multimedia files and information while mobile has introduced even more questions that will need to be studied. At present, there are already several studies on the way people use the camera phones and which type of message do people create and send. For instance, Kindberg, Spasojevic, Fleck, and Sellen [19], conducted an in-depth research using interviews and discussions about a sample of real user's photos. They created a 6-part taxonomy to describe the way images are use "both for sharing and personal use, and for affective and functional use". According to the authors, the main usages could be Social or Individual. The social usages cold be classified as Affective (to share mutual experiences or to link with an absent friend or family) or Functional (for mutual tasks or for remote tasks). The Individual usages were found to be mainly for Personal Reflection or for Personal Tasks. Other example is [20], where the authors described emerging practices with camera phones in Japan illustrating these practices with ethnographic material. This research is still in early stages (as the adoption of these technologies) and we still not do know if these exchange on information has any effect on the use of multimedia in the communication's pattern of these communities.

In addition to all these challenges, very recently we have seen the launch of new applications that will allow us to connect to some of the features of the social networks from the mobile. For instance, from early this year we can receive alerts whenever a new comment is added to your MySpace page, or you can upload images from your mobile to Flickr. These new developments have brought some business analyst: "Could mobile social networks be the next big thing?" [21]. A new term of mobile social networks have emerged, which according to [22] is "a network of interpersonal ties that provides sociability, support, information, a sense of belonging, social identity, and which always connects its members regardless of where they go." Indeed, it already exist some exclusively mobile-based mobile social networks as the one operated buy AirG [23], Jumbuck [24], and Trilibis Mobile [25].

As social software has increases its usage in the last years, some researchers are staring to research questions, coming directions and relevant technologies surrounding the adoption of this type of software. The main example of this emerging research area is the workshop that was hold during CHI 2006 about "Mobile Social Software. In their conclusions, the workshop organisers stated that the primary discussion topics that will need to be investigated are [26]: "Antisocial Mobile Software; Supporting special communities; Mobile social awareness and presence; Mobile support for multiple cultures (i.e. Mobile support for "cultural translation" on the fly); Personal projectors (co-located, multi-user applications); Supporting 
epidemiology (i.e. combating spreading of disease); and Barriers (critical mass, interoperability)". Most of these challenges lied in the software development site. We did not find information about mixed presence and virtual communities.

\section{Physical Communities with Technological Support}

We have found a research gap while searching for data about the relationships that may exist between physical communities with technological support and their communication patterns (or any other characteristic) of these communities in the real world. In recent years a number of applications of mobile technologies tried to explore the relationship between location-based communities and virtual means of communication. For instance, a group of finish young people, led by Jyri Engestrom, started a club in Helsinki where they combined the physical location, virtual community and SMS. The "Aula" [3] allows the contact face to faces with groups of people that meet physically at the club, but it also allows the contact among the members of the group not physically present in the club through mobile communications. Other examples are, "ImaHima" (are you free now?) [4], which allow I-mode users in Tokio to send a message to their friends that are physically close at a particular time. COSMOS [2] is project with the stated goal of offering the mobile support of communities. Their activities were based on the development of generic services and technologies for operating mobile communities. They established two pilot communities in the domains Lifestyle and Healthcare. The main focus of the application domain "Lifestyle" was mobility-driven recreation behaviour.

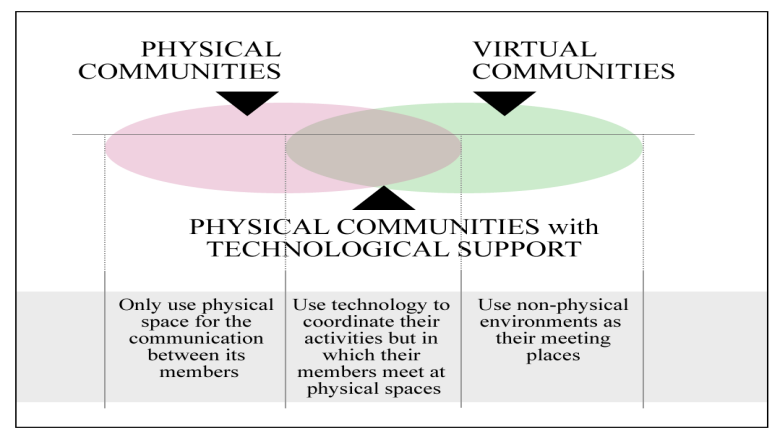

Fig. 2. Types of communities according to the ways of communication of their members

In fact, there are not many studies about how electronic support can help physical communities' communications. It is known that mobile phones, email, forums, chats, etc. help people to plan community activities, meetings and etc; but we have not found empirical data to scientifically prove the impact of the usage of these technologies in their communication patterns or any other intrinsic characteristic of the community.

One example of the studies that claim that the usage of IT could help the performance of physical communities is the work by Sproull and Patterson [27] 
regarding Boy Scouts groups. The assumption behind is that if the members can begin to participate electronically in local groups, they may become more motivated to do so in the physical world. Nevertheless, we have not been able to find data that prove this well extended claim.

Therefore, we conclude that further research would bee needed to understand with empirical data from the live of location based (what we called physical) communities the impact of the use of innovative technologies. Only after accumulative research in this area we would be able to understand if the impact of technology in the physical communities is related to body of knowledge that we have about virtual communities.

\section{Our UCD Approach}

After the review of the literature in the area that we have summarise in the previous sections, our hypothesis is that in order to understand how technology could help and the impact that technology, and in particular mobile multimedia technologies, have in the communication patterns and life of a physical community we need to follow a complete User Centred Design Cycle. Our research in ICING has been centred in investigating the impact of social and human factors on ways of establishing communication among the members of communities with technological support in Barcelona. We followed a UCD approach our research in ICING which will involve 3 phases: (1) User requirements and creation of scenarios for new services; (2) Prototyping the services; and (3) User trials.

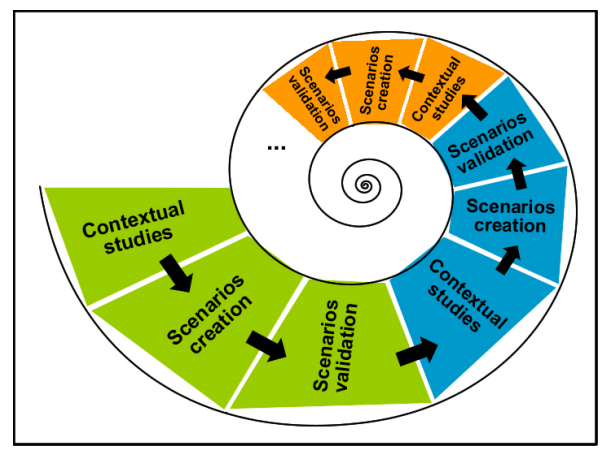

Fig. 3. Methodological approach for scenario creation and validation in ICING

We will present here the work done during phase (1); as we are currently starting phase (2). For this first phase the methodology involved observing people in their own environments, where people behave more naturally and where we can explore surroundings and artefacts to add validity to the collected data. Through field research we will gain a deeper understanding of people needs and expectances. In our research we have gathered data from real prospective users in real urban spaces and different social networks: we conducted observational studies to obtain user requirements to improve mobile services between community members to enhance their cohesion and relationship. This task had a specific focus on disadvantaged social groups (women 
associations and elderly people) with the aim of identifying broader support measures needed to ensure services acceptance by all citizens.

In this section we will briefly describe the process followed. The identification of the communities in the Barcelona city was done thanks to the studies carried on by municipal and public entities, that have direct contact with the communities and that know their contact people and processes. Once communities were identified we interviewed and observed the members of these two selected communities groups. The aim of having this two steps approach was that the community responsible would provide us information about community's members and dynamics, allowing us to discover preliminary user cases and scenarios that were them validated and enlarged s we approached the community members, as we illustrate in Figure 3.

\section{Data from City-Based Communities}

We will describe the research with two communities of people based on Barcelona.

\subsection{Women Associations}

We have visited 9 women associations and an approximate total of 50 associate. The typical profile of the women associated to most Women associations is: married housewives and older than 50 years. Younger women do not use to participate at this associative level. The main aim of women organizations is to help each other to grow and confront common problems and concerns in their lives, typically from one are of the neighbourhood. These associations are also very active in the social life of the community, giving support to most of the special events that occur in the neighbourhood and a lot of initiatives from the city council.

- Actual patterns of communication: Although the communication among the members of the association is very intense (p.e. to announce a talk, to invite them to attend a meeting, etc), most of these exchanges are done over the phone. At present, they use "telephone chains" (i.e. person A calls person B, person B calls person $\mathrm{C}$, etc.) to communicate urgent notices among them, creating recursive communication problems. They do not use email and their usage of PCs is very low. They have problems exchanging multimedia material.

- Detected problem: (1) Women need an effective way of communication between them for two main types of communication: communication with all the associates to share information related to their association life and activities; and for communicating with the association because they need to find a person that have do a particular job. (2) They will like a way to share multimedia information.

- Solution: Create a mobile service for women to (1) keep in touch anytime and anywhere in case of one of them needs something and (2) enable them to exchange multimedia content (p.e. send video of their activities live to the members of the community wherever they are and being able to archive these information). During our interviews we also gather information about the need to 
expand this service so that it could also be used to find the nearest person of a concrete community.

\subsection{Elderly People}

We contacted two Day Centre for retired people ("Casal") as they organize most of the activities targeted for elderly people. One of the "Casal" has more tham 500 elderly people associated to it, which represents almost $90 \%$ of the elderly population in this part of town. We interviewed 25 elders. Most of the associates are widow and they life alone or married couple living together. Most of the women and men go to the Day Centre to play table-games, to talk, etc. In addition, the "Casal" organises day out excursions, courses (paining, singing, internet, etc.), concerts, parties, etc.

- Social communication needs: Elderly whose family lives far away from their home would like to see their relatives more often, but due to distance and mobility problems it is quite difficult to meet them frequently. They use fix and mobile phones to stay in regular contact, but they miss seeing them. A similar thing happens when the family is on holiday, because despite they communicate by phone, they would like to receive images and videos from where they are spending their holidays to see the landscapes and place they visit, and to see their beloved ones there. In addition, quite often they cannot go to the "Casal" and they miss meeting with their friends, and having contact with them.

- Detected problem: We have detected several problems: (1) Be in touch with their family and the community at the "Casal". They reported that the problem is that their family are not usually at home and they can not always go to the "Casal". (2) Be aware if some of the activities to which they are inscribed is cancelled at last minute and to remind them the activities they want to attend

- Solution: (1) ICING system will allow them to receive video and images from their loved ones. They would have the possibility of saving them and classify them, and revisit this multimedia material. The key factor here is that they would not want to send images or videos themselves, just to have the possibility to passively receive them. (2) ICING services will present travel information in their mobile phones, new ways or interaction are being researched.

Because of the scope of this paper we will not be able to present here the scenarios that explain in detail how the ICING system works in each case.

\section{Conclusions}

As we stated previously our goal is understand how technology, especially mobile multimedia technology, can enhance the communication and other aspects among physical communities. We have found a research gap regarding empirical data about the impact of mixing virtual and physical communities through mobile multimedia (images and video) communication technologies. We claim that in order to generate accumulative knowledge to address this gap more research is needed following an UCD approach to the implementation of new technologies. The focus of our work was on women associations and elders. In a later stage, we will broader our 
communities' sample to ensure that the proposed services will be acceptance by all citizens. In brief, after performing detailed contextual research in the selected communities, we found that both of these communities have a need for informal communications while they are not together and they are "on the move". These informal communications depend on the characteristics of e and required different type of services for each community:

- $\quad$ Services that help community members to strength cohesion between them, as a whole (inner services). More useful for Women associations.

- Services that are intended for individuals of a concrete community. These services do not relate the members of the community with other members of the community, but with people outside of the community (in-to-out services). More wanted by Elderly people.

In the light of these data, our claim is that the need for this informal communication while they are mobile could be fulfilled by video communication. We are, at present, investigating multimodal interfaces and technological architectures that would allow us to gather evidence in support of this claim. We are now in phase 2 of the project, which includes two main tasks:

- Research on user interfaces that would allow this information to be presented in an intuitive and easy to interact way.

- Development of the test beds that will allow us to test the acceptance and efficiency of the proposed services in solving the real problems that we found.

Acknowledgement. We are grateful for the EU support in the frame of the ICiNG project, IST-200424 26665, and to all the partners in ICiNG. We also want to thank the communities and associations that gently have collaborated with our research.

\section{References}

[1] Workshop CHI2006. Investigating new user experience challenges in iTV: mobility and sociability (2006) http://soc.kuleuven.be/com/mediac/chi2006workshop/papers.htm

[2] Koch, M., Groh, G., Hillebrand, C., Fremund, N.: COSMOS (Community Online Services and MObile Solutions) Mobile Support Lifestyle Communities. Arbeitsberichte des Lehstuhls für Allegemeine und Industrielle Betriebswirschaftslehre an der Technischen Universität München (2002)

[3] Aula (n.d.).: Retrieved September 7th, 2006 from http://www.aula.cc

[4] ImaHima (n.d.).: Retrieved September 7th, 2006 from http://www.imahima.com

[5] Community types (n.d.): Retrieved September 7th, 2006 from http://virtualcommunities.com

[6] Defining Communities (n.d.).: Retrieved September 7th, 2006 from http://virtualcommunities.com

[7] Kim, A.J. (n.d.).: Calling all community builders (2006). Retrieved September 7th, 2006 from http://www.naima.com

[8] Bishop, J. (n.d.).: Online communities are often real communities. (2006) Retrieved September 7th, 2006 from http://www.jonathanbishop.com/Web/Weblog/ Default.asp?MID=1\&NID=59 
[9] Kim, A.J. (n.d.).: Community building on the web. Roles: from newcomer to oldtimer (2006) Retrieved September 7th, 2006 from http://www.naima.com

[10] Boetcher, S., Duggan, H., White, N. (n.d.).: (2006) What is a Virtual Community and Why Would you Ever Need One??. Retrieved September 7th, 2006 from http://www.fullcirc.com/community/communitywhatwhy.htm

[11] Fish, R.S., Kraut, R.E., Root, R.W., Ronald E.: Rice Evaluating Video as a Technology for Informal Communication Studies of Media Supported Collaboration. In: Proceedings of ACM CHI'92 Conference on Human Factors in Computing Systems pp. 37-48 (1992)

[12] Veinott, E.S., Olson, J.S., Olson, G.M., Fu, X.: Video Matters! When communication is stressed video Helps. In: Abstracts of CHI '97, Atlanta GA, pp. 315-316. ACM Press, Newyork (April 1997)

[13] Finn, K., Sellen, A., Wilbur, S. (eds): Video Mediated Communication,Hillsdale, NJ (1997)

[14] Marcus Credé Janet, A.: Sniezek Group judgment processes and outcomes in videoconferencing versus face-to-face groups. International Journal of Human-Computer Studies 59(6), 875-897 (2003)

[15] Olson, J.S., Olson, G.M.: Face-to-face group work compared to remote group work with and without video. In: Finn, K., Sellen, A., Wilbur, S. (eds.) Video Mediated Communication, Lawrence Erlbaum Associates, Hillsdale, NJ (1997)

[16] Toward determining an attention getting device for improving interaction during videomediated communication Fels, D.I.1 and Weiss, P.L.2 1 Ryerson Polytechnic University, Toronto, Canada 2 Hadassah-Hebrew University, Jerusalem, Israel http:// www.telbotics.com/research_5.htm

[17] Castillo, J.: (2007) Power, wifi and ideas. Retrieved February 13th, 2007 from http://www.thinkjose.com/2006/10/

[18] YouTube: http://www.youtube.com/

[19] Kindberg, T., Spasojevic, M., Fleck, R., Sellen, A.: The Ubiquitous Camera: An In-depth Study of Camera Phone Use. IEEE Pervasive Computing, special issue on The Smart Phone (April-June, 2005)

[20] Okabe, D., Itto, M.: (I print) Everyday Contexts of Camera Phone Use: Steps Toward Technosocial Ethnographic Frameworks. In: Höflich, Joachim and Hartmann, Maren Eds. Mobile Communication in Everyday Life: An Ethnographic View. Berlin: Frank and Timme

[21] blog, B.B.: Could mobile social networks be the next big thing? Retrieved September 7th, 2006 http://www.mobileactive.org/node/2357

[22] Mobile Design Communities.: Retrieved January 12t 2007 from http:// www.mobilecommunitydesign.com/pages/faq.html\#1

[23] AirG: http://www.airg.com/, [24] Jumbuck: http://www.jumbuck.com, [25] Tribilis Mobile: http://www.trilibis.com/

[24] Counts, S., ter Hofte, H., Smith, I.: Retrieved May 20th, 2006 from http://chi2006mososo.telin.nl/index.html

[25] Sproull, L., Patterson, J.F.: Making information cities livable. Communications of the ACM 47(2), 3337 (2004) 